\title{
Effect of Nitrogen on the High Temperature Creep Behavior of 9Cr-2Co Steel
}

\author{
Ken-ichiro HARA, Hajime AOKI, ${ }^{1)}$ Fujimitsu MASUYAMA ${ }^{2)}$ and Takao ENDO ${ }^{3)}$ \\ Graduate School, Yokohama National University, Tokiwadai, Hodogaya-ku, Yokohama, Kanagawa-ken, 240 Japan. \\ 1) Formerly Graduate School, Yokohama National University. Now at Kawasaki Heavy Industries Ltd., Minamisuna, Koto-ku, \\ Tokyo, 136 Japan. $\quad$ 2) Nagasaki Research and Development Center, Mitsubishi Heavy Industries, Ltd., Hukahori-cho, \\ Nagasaki, Nagasaki-ken, 851-03 Japan. $\quad 3)$ Department of Mechanical Engineering and Material Science, Yokohama \\ National University, Tokiwadai, Hodogaya-ku, Yokohama, Kanagawa-ken, 240 Japan.
}

(Received on July 18, 1996; accepted in final form on November 12, 1996)

\begin{abstract}
Constant load creep tests were conducted at 873,898 and $923 \mathrm{~K}$ under an initial stress of 50,60 or $70 \mathrm{MPa}$ to examine the effect of nitrogen addition $(0.06,0.11,0.16$ and 0.19 mass $\%)$ on the creep behavior of a 9 mass $\% \mathrm{Cr}-2 \mathrm{mass} \% \mathrm{Co}$ ferritic steel. Extraction residue analysis showed that 240 to $410 \mathrm{ppm}$ of nitrogen was present as solid solution. The rest of the nitrogen existed as nitride precipitates. The creep rate decreased while creep rupture life increased with an increase in nitrogen content. It is also observed that the higher the nitrogen, the shorter the creep rupture strain. A state equation for creep could be represented as; $\dot{\varepsilon}_{0}=A_{0} \sigma_{0}^{n} \exp \left(-Q_{0} / R T\right)$, where $\dot{\varepsilon}_{0}$ is the imaginary initial strain rate defined in the text, $A_{0}$ is a constant, $n$ is the stress exponent and $Q_{0}$ is the apparent activation energy. The mean values of $n$ and $Q_{0}$ were 4.5 and $360 \mathrm{~kJ} / \mathrm{mol}$, respectively. The Orowan stress for specimens crept at $873 \mathrm{~K}$ and $70 \mathrm{MPa}$ was estimated from the measurement of mean interparticle spacing obtained by TEM study. The resultant values are $15,22,30$ and $38 \mathrm{MPa}$ for specimens containing $0.06,0.11,0.16$ and 0.19 mass\% nitrogen, respectively.
\end{abstract}

KEY WORDS: high temperature creep; ferritic heat resisting steel; nitrogen-saturated steel; imaginary initial strain rate; stress acceleration factor; I-S effect.

\section{Introduction}

Austenitic heat-resisting steels have been extensively used as boiler tubes or steam turbine rotors in many power plants. These alloys have superior strength at a temperature range of about 773 to $873 \mathrm{~K}$, but also show some disadvantages such as the tendency to stress corrosion cracking in a chloride ion atmosphere or spalling of the inside scale which is formed by steam oxidation. ${ }^{1)}$ In addition, because of their large heat expansion coefficients, fatigue damage due to reversible thermal stress will give rise to serious problems when daily start and stop (DSS) operation starts at these plants in the near future.

With these points as a background, the development of ferritic heat-resistant steels has been desired as a replacement material for austenitic steels. Though so far 9 to 13 mass \% Cr steel alloys have been attempted for practical usage, their service temperature is still limited to about $870 \mathrm{~K}$.

Aiming at higher service temperatures, researches on high chromium ferritic steels containing nitrogen have been prosperously done. ${ }^{2,3)}$ As for the beneficial effects of nitrogen for high temperature creep strength in these steels, two types of strengthening mechanism have been proposed. One is the solid solution hardening at elevated temperatures and the other is the precipitation hardening.
The origin of the former strengthening is attributable to the increase of the resistance to dislocation motion. ${ }^{4)}$ This is because there is a possibility of Interstitial-Substitutional (I-S) pairs to be formed by a chemical interaction between interstitial nitrogen and substitutional chromium atom. ${ }^{4)}$ Once these pairs are formed around dislocations, mobile dislocations have to drag their atmospheres behind them. In practice, Motoyoshi et al. $^{5)}$ have demonstrated the effect of nitrogen on the creep behavior of $\alpha \mathrm{Fe}-\mathrm{Mo}-\mathrm{N}$ and $\alpha \mathrm{Fe}-\mathrm{W}-\mathrm{N}$ solid solution alloys and they have ascribed it to the I-S effect. On the other hand, it has been pointed out that an addition of nitrogen to ferritic heat resistant steels enhances the thermal stability of fine precipitates and eventually the precipitation hardening lasts to fairly longer time. ${ }^{6)}$ As mentioned above, there is a possibility that two different strengthening mechanisms are operating simultaneously in a heat resistant steel with forcibly introduced high nitrogen.

The purpose of the present study is to investigate the effect of forcibly introduced nitrogen on the imaginary initial creep rate, which is equivalent to the steady state creep rate in principle, ${ }^{7)}$ and to discuss the role of nitrogen present as precipitates and solid solution in a $9 \mathrm{Cr}-$ 2 Co steel. 
Table 1. Alloy designation and chemical composition in mass $\%$.

\begin{tabular}{|c|c|c|c|c|c|c|c|c|}
\hline \multirow{2}{*}{ Designation } & \multicolumn{3}{|c|}{ Alloying elements (mass\%) } & \multicolumn{5}{|c|}{ Impurities (mass \%) } \\
\hline & $\mathrm{Cr}$ & Co & $\mathrm{N}$ & $\mathrm{C}$ & $\mathrm{Si}$ & $\mathrm{Mn}$ & S & $P$ \\
\hline NI & 8.9 & 2.0 & 0.06 & 0.001 & 0.002 & 0.01 & 0.002 & 0.005 \\
\hline N2 & 9.0 & 2.0 & 0.11 & 0.005 & 0.002 & 0.006 & 0.001 & 0.004 \\
\hline N3 & 8.9 & 1.9 & 0.16 & 0.008 & 0.004 & 0.009 & 0.001 & 0.004 \\
\hline N4 & 8.8 & 1.9 & 0.19 & 0.009 & 0.005 & 0.009 & 0.001 & 0.004 \\
\hline
\end{tabular}

\section{Experimental Procedure}

\subsection{Specimen}

A steel ingot, whose composition was $9 \mathrm{mass} \% \mathrm{Cr}-$ 2 mass $\% \mathrm{Co}-0.05$ mass $\% \mathrm{~N}$ was obtained by a vacuum melting process. A part of the ingot was separated and re-melted in an argon-nitrogen atmosphere under a pressure of $1.1 \mathrm{MPa}$. By adjusting the partial pressure of nitrogen, 0.06 to $0.2 \%$ nitrogen was forced to dissolve into the molten steel. The resultant steels were hot forged and then hot-rolled into sheets of $3 \mathrm{~mm}$ in thickness. Cobalt was added to obtain the tempered martensite structure irrespective of nitrogen concentration. The creep specimens were cut from these plates with their tensile axis parallel to the rolling direction.

Austenitization was carried out at $1423 \mathrm{~K}$ for $1800 \mathrm{sec}$ and followed successively by annealing at $973 \mathrm{~K}$ for $1800 \mathrm{sec}$. After these heat treatments, all specimens showed a tempered martensite structure. Table 1 shows the chemical compositions of each specimen. Hereafter, specimens containing $0.06,0.11,0.16$ and 0.19 mass $\%$ nitrogen will be designated N1, N2, N3 and N4, respectively. Quantitative analysis of soluble nitrogen and chromium in matrix was conducted by an extraction residue method for each specimen before creep testing. The results of the analysis are given in Table 2 . It is found that 240 to $410 \mathrm{ppm}$ of nitrogen is present as a solid solution.

\subsection{Creep Test}

Creep testing was carried out under constant loads with a simple lever type creep tester. The testing temperature was controlled by an electric tube furnace parted with different heat sources. The difference in temperature between upper and lower sides of the furnace was kept within $\pm 1 \mathrm{~K}$. Elongation was recorded automatically by a dial gauge with an accuracy of $1 / 100 \mathrm{~mm}$. Creep conditions were from 873 to $923 \mathrm{~K}$ at stress of 50,60 or $70 \mathrm{MPa}$.

\subsection{Observation of Microstructure}

Microstructures after creep testing were observed by transmission electron microscopy operated at $200 \mathrm{kV}$. The thin foils for TEM were prepared by a twin jet electropolishing in a mixture of $5 \mathrm{vol} \%$ perchloric acid and $95 \mathrm{vol} \%$ acetic acid.

\section{Experimental Results}

\subsection{Creep Curve}

Typical creep curves obtained at an initial stress of $50 \mathrm{MPa}$ are shown in Figs. 1(a) and 1(b). It is seen that
Table 2. Soluble nitrogen contents in ppm

\begin{tabular}{ll}
\hline N1 & 240 \\
N2 & 330 \\
N3 & 330 \\
N4 & 410 \\
\hline
\end{tabular}

(a)

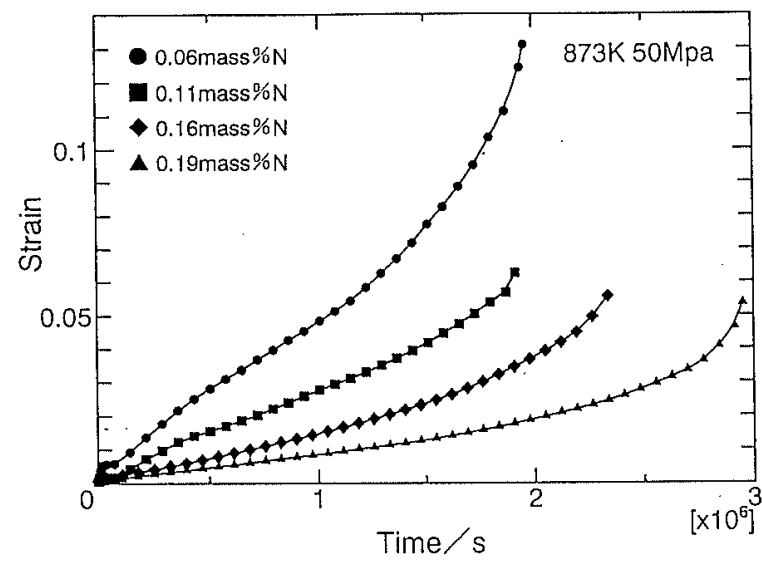

(b)

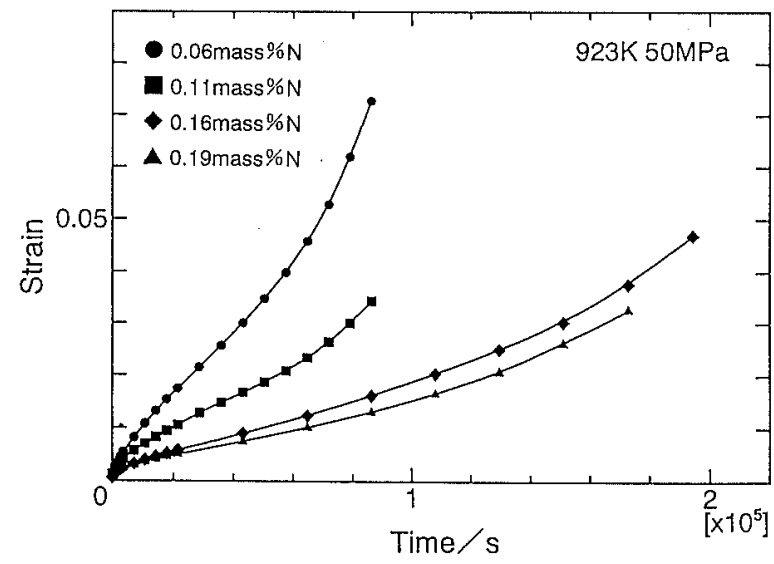

Fig. 1. Effect of nitrogen addition on creep curve at (a) $873 \mathrm{~K}$, $50 \mathrm{MPa}$ and (b) $923 \mathrm{~K}, 50 \mathrm{MPa}$.

the creep rate decreases while the creep life tends to increase with an increase in nitrogen concentration. Such a beneficial effect of nitrogen was ascertained under various experimental conditions. The instantaneous creep strain, creep life, creep rupture strain, and reduction of area obtained are summarized in Table 3.

As shown in Fig. 1(b) and Table 3, the creep life of N4 is sometimes a little bit shorter than that of N3. Therefore, it can be said that a nitrogen addition more than $0.16 \%$ is not so effective in creep life extension. As for the creep rupture strain, the addition of nitrogen 
Table 3. Summary of creep tests.

\begin{tabular}{|c|c|c|c|c|c|c|}
\hline Designation & $\begin{array}{l}\text { Temp. } \\
\text { (K) }\end{array}$ & $\begin{array}{l}\text { Initial stress } \\
\quad(\mathrm{MPa})\end{array}$ & $\begin{array}{l}\text { Instant strain } \\
(\%)\end{array}$ & $\begin{array}{l}\text { Creep life } \\
\text { (h) }\end{array}$ & $\begin{array}{c}\text { Rupture strain } \\
(\%)\end{array}$ & $\begin{array}{l}\text { Reduction of area } \\
(\%)\end{array}$ \\
\hline N1 & 873 & 50 & 0.08 & 545.5 & 16.3 & 4.1 \\
\hline \multirow[t]{3}{*}{0.06 mass $\% \mathrm{~N}$} & 873 & 60 & 0.03 & 265.5 & 10.3 & 5.2 \\
\hline & 873 & 70 & 0.08 & 74.4 & 16.0 & 14.0 \\
\hline & 923 & 50 & 0.06 & 25.8 & 13.0 & 13.0 \\
\hline N2 & 873 & 50 & 0.06 & 532.0 & 7.7 & 1.1 \\
\hline \multirow[t]{3}{*}{0.11 mass $\% \mathrm{~N}$} & 873 & 60 & 0.01 & 171.0 & 4.7 & 3.0 \\
\hline & 873 & 70 & 0.06 & 66.1 & 8.0 & 11.0 \\
\hline & 923 & 50 & 0.14 & 25.3 & 7.0 & 7.0 \\
\hline N3 & 873 & 50 & 0.10 & 652.0 & 8.5 & 2.7 \\
\hline \multirow{3}{*}{0.16 mass $\% \mathrm{~N}$} & 873 & 60 & 0.03 & 268.9 & 5.0 & 2.3 \\
\hline & 873 & 70 & 0.06 & 116.7 & 5.0 & 2.0 \\
\hline & 923 & 50 & 0.07 & 55.9 & 8.0 & 5.0 \\
\hline N4 & 873 & 50 & 0.10 & 819.3 & 7.3 & 4.1 \\
\hline \multirow[t]{3}{*}{0.19 mass $\% \mathrm{~N}$} & 873 & 60 & 0.10 & 246.2 & 4.0 & 0.9 \\
\hline & 873 & 70 & 0.11 & 107.0 & 6.0 & 3.0 \\
\hline & 923 & 50 & 0.08 & 51.5 & 5.0 & 1.0 \\
\hline
\end{tabular}

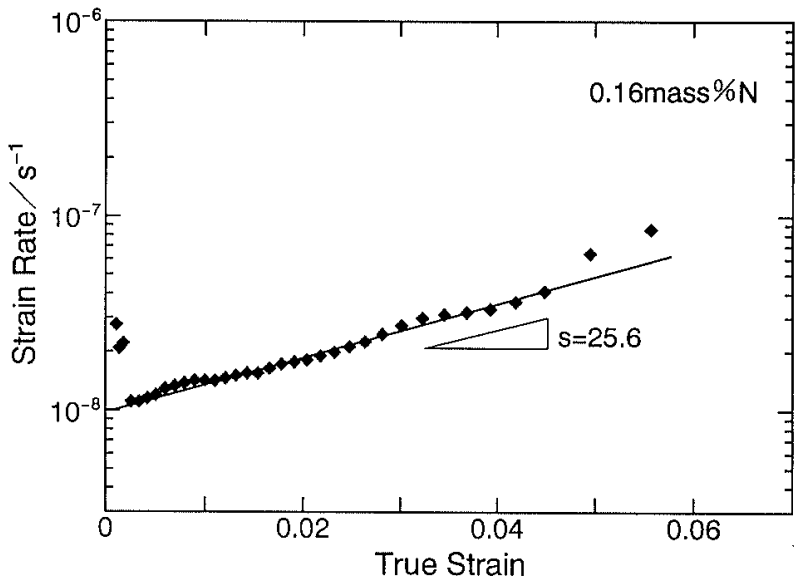

Fig. 2. Relationship between logarithm of strain rate and the true strain at $50 \mathrm{MPa}$ and $873 \mathrm{~K}$.

appears to be harmful: the creep rupture strain of N1 is $16 \%$ at the maximum whereas those of $\mathrm{N} 2$ to $\mathrm{N} 4$ are less than $8.5 \%$. The ruptured specimens exhibit brittle fracture surface over the whole cross sectional area.

\subsection{Relationship between Strain Rate and True Strain}

Recent studies on a $2.25 \mathrm{Cr}-1$ Mo steel have shown that the logarithm of creep rate is proportional to true strain over the almost entire creep life. ${ }^{7)}$ Here, the same type of analysis will be applied to the present steels. The examples are shown in Fig. 2. It is seen that a single straight line can be drawn except for the early and last stages of creep. Discarding the data sets of the early and the last $10 \%$ of rupture strain, the intercept with zero strain and the slope of the line was determined by the least square method. Hereafter, the $\mathrm{Y}$-intercept and the slope will be named an imaginary initial creep rate, $\dot{\varepsilon}_{0}$, and a strain rate acceleration factor, $S$, respectively.

Using the symbols defined above, the straight line is expressed in the form;

$$
\dot{\varepsilon}=\dot{\varepsilon}_{0} \exp (S \varepsilon) \text {. }
$$

The values of $S$ and $\dot{\varepsilon}_{0}$ obtained were determined under
Table 4. Imaginary strain rates and strain rate acceleration factors.

\begin{tabular}{|c|c|c|c|c|c|c|}
\hline \multirow{2}{*}{$\frac{873 \mathrm{~K}}{\text { Designation }}$} & \multicolumn{2}{|c|}{$50 \mathrm{MPa}$} & \multicolumn{2}{|c|}{$60 \mathrm{MPa}$} & \multicolumn{2}{|c|}{$70 \mathrm{MPa}$} \\
\hline & $\dot{\varepsilon}_{0}\left(\mathrm{~s}^{-1}\right)$ & $S$ & $\dot{\varepsilon}_{0}\left(\mathrm{~s}^{-1}\right)$ & $S$ & $\dot{\varepsilon}_{0}\left(\mathrm{~s}^{-1}\right)$ & $S$ \\
\hline NI & $2.19 \mathrm{E}-8$ & 15.4 & 8 & 14 & & 21.0 \\
\hline N2 & $1.75 \mathrm{E}$ & 18.2 & $3.25 \mathrm{E}-8$ & 26.2 & $7.88 \mathrm{E}-8$ & 31.2 \\
\hline N3 & $1.21 \mathrm{E}-8$ & 25.6 & $1.76 \mathrm{E}-8$ & 44.3 & $3.74 \mathrm{E}-8$ & 41.7 \\
\hline N4 & $5.10 \mathrm{E}-9$ & 54.2 & $2.26 \mathrm{E}-8$ & 35.8 & $3.28 \mathrm{E}-8$ & 47.9 \\
\hline
\end{tabular}

various creep conditions and they are summarized in Table 4. Close inspection of Table 4 shows that the value of $\dot{\varepsilon}_{0}$ tends to decrease while that of $S$ increases with an addition of nitrogen being compared under the same test condition as far as the specimens of N1 to N3 are concerned. As for $\mathrm{N} 4$, the value of $\dot{\varepsilon}_{0}$ at $60 \mathrm{MPa}$ is extraordinarily higher than that expected from the other data. The reason is not clear but this appears to be related to the smaller $S$ value at $60 \mathrm{MPa}$. Since the number of specimens was quite limited in the present study, the reason for the anomalous behavior of N4 could not be examined. Therefore, N4 will be omitted thoroughly in the subsequent analysis. For a given concentration of nitrogen, $\dot{\varepsilon}_{0}$ increases with stress and temperature and $S$ tends to increase slightly with stress.

\subsection{Stress and Temperature Dependence of $\dot{\varepsilon}_{0}$}

Figure 3 shows the relationship between $\dot{\varepsilon}_{0}$ and initial stress on a double logarithmic scale. The relation between the imaginary initial strain rate and stress can be expressed in the form;

$$
\dot{\varepsilon}_{0}=A \sigma_{0}^{n},
$$

where $A$ is a constant depending on temperature, $n$ is the stress exponent, and $\sigma_{0}$ is the initial stress. It is seen from Fig. 3 that the value of $n$ is 5.0, 4.5 and 3.9 for N1, $\mathrm{N} 2$ and $\mathrm{N} 3$, respectively and it decreases with the increase of nitrogen content.

In order to determine the temperature dependence of 


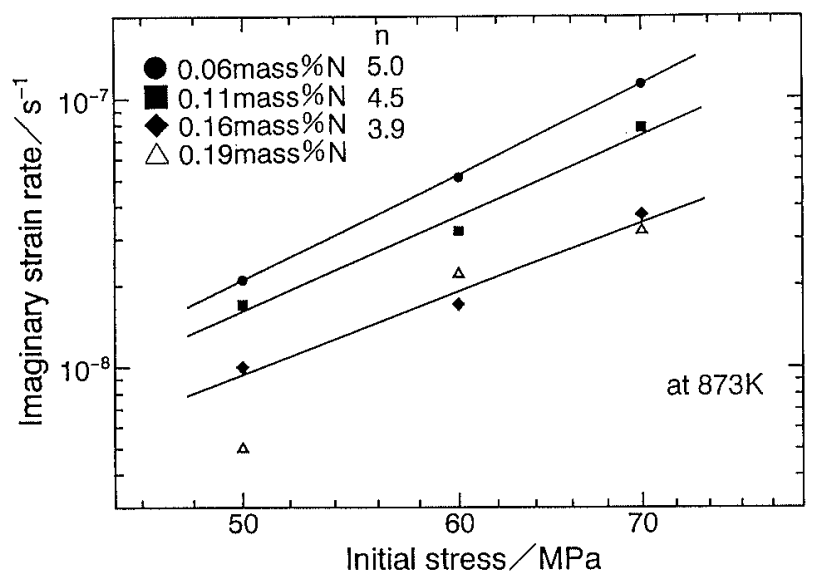

Fig. 3. Double logarithm plot of imaginary initial strain rate against initial stress. The symbol $n$ designates the slope of the lines.

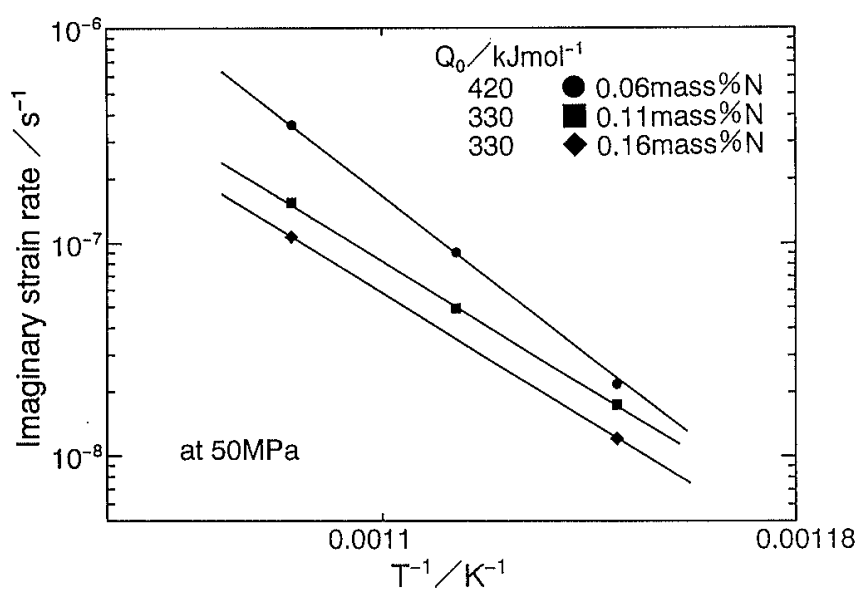

Fig. 4. Arrhenius plot of imaginary initial strain rate at $50 \mathrm{MPa}$. The apparent activation energies are given in the figure.

$A$, an Arrhenius plot was attempted. The result is shown in Fig. 4. Here, creep data of N1 and N2 at $893 \mathrm{~K}$ and $50 \mathrm{~Pa}$ were added to get more confident slope of these lines. A good linear relation is obtained. From this fact, the temperature dependence of the imaginary initial strain rate can be expressed in the form;

$$
\dot{\varepsilon}_{0}=B \exp \left(-Q_{0} / R T\right),
$$

where $B$ is a constant and $Q_{0}$ is the apparent activation energy. The measured value of $Q_{0}$ is about 420,330 and $330 \mathrm{~kJ} / \mathrm{mol}$ for $\mathrm{N} 1, \mathrm{~N} 2$ and N3, respectively. It is to be noted that the value of $Q_{0}$ for $\mathrm{N} 1$ is about $90 \mathrm{~kJ} / \mathrm{mol}$ larger than those of $\mathrm{N} 2$ and N3.

\subsection{Microstructure}

TEM micro-graphs of the specimens crept at $873 \mathrm{~K}$ and $70 \mathrm{MPa}$ are shown in Fig. 5. In the case of N1, the dislocation density within grains is relatively low and fine spherical precipitates are seen within grains while some larger elliptical coarse particles are also seen along grain boundaries. In the case of $\mathrm{N} 2$, the dislocation density is higher than that of $\mathrm{N} 1$ and needle-like precipitates with a length of about a few hundred nano meters are observed. In the case of N3 and N4, needle-like precipitates are uniformly dispersed within grains but the
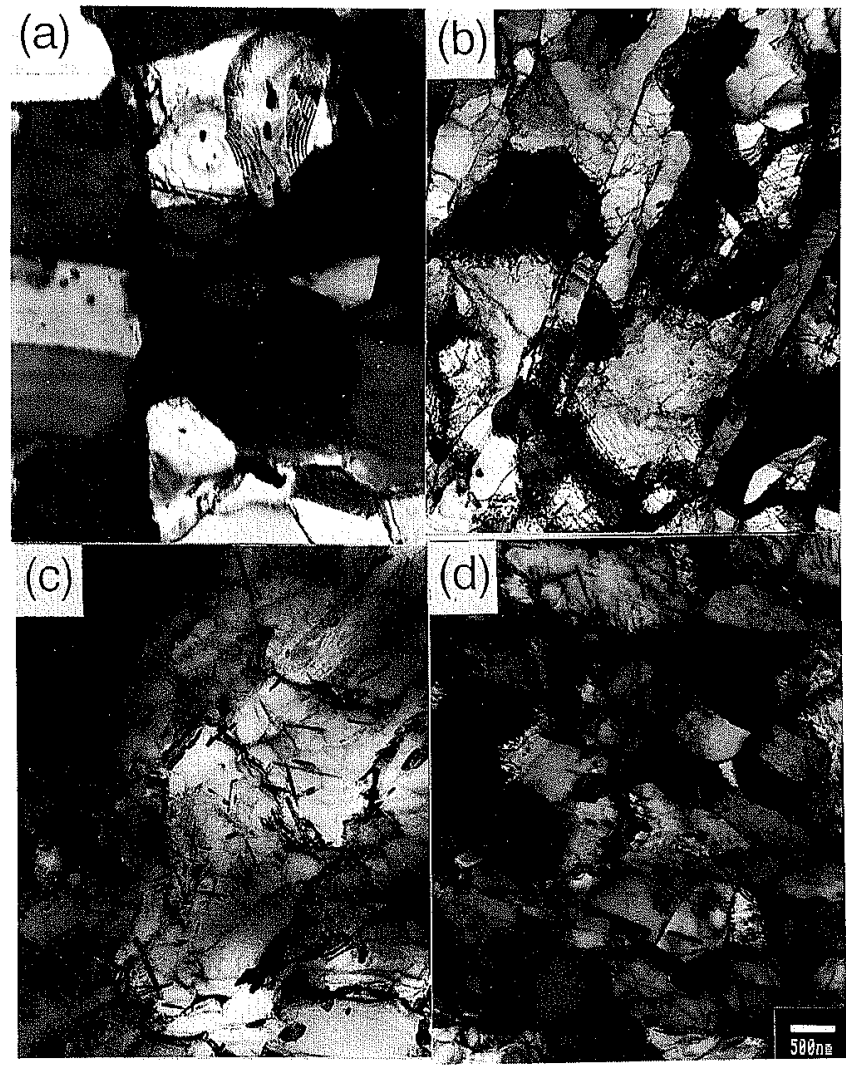

Fig. 5. TEM micro structures of (a) N1, (b) N2, (c) N3 and (d) N4 after creep test at $873 \mathrm{~K}$ and $70 \mathrm{MPa}$.

Table 5. Distribution parameters estimated from the TEM study. The symbol $\bar{r}, \vec{r}^{2}$ and $\bar{r}^{3}$ are the average of $r, r^{2}$ and $r^{3}$, respectively. Also the symbol $T_{\mathrm{s}}$ and $\bar{r}_{\mathrm{s}}$ are the average of distance between the particle centers and the radii cut by the slip plane, respectively.

\begin{tabular}{crccccc}
\hline Designation & Total No. & $\bar{r}$ & $\tilde{r}^{2}$ & $\bar{r}^{3}$ & $\bar{l}_{\mathrm{s}}$ & $\bar{r}_{\mathrm{s}}$ \\
\hline N1 & 44 & 1.46 & 2.39 & $4.2 \mathrm{I}$ & 9.29 & 1.28 \\
N2 & 75 & 0.73 & 0.64 & 0.63 & 5.49 & 0.69 \\
N3 & 213 & 0.84 & 0.85 & 1.00 & 3.20 & 0.79 \\
N4 & 88 & 0.74 & 0.72 & 0.86 & 2.17 & 0.70 \\
\hline
\end{tabular}

dislocation density is higher in N4. Here, the quantitative measurements of the mean spacing between precipitates and the mean particle radius were estimated by the method reported by Yeh et al. ${ }^{8)}$ which regards the distribution of particle radius. For the elliptical and the needle like precipitates, the radii in the transverse section were measured. The resultant parameters are summarized in Table 5.

\section{Discussion}

\subsection{State Equation for Creep}

4.1.1. Imaginary Initial Strain Rate

From Eqs. (2) and (3) which are both derived on the experimental basis, the imaginary strain rate is expressed as follows;

$$
\dot{\varepsilon}_{0}=A_{0} \sigma_{0}^{n} \exp \left(-Q_{0} / R T\right),
$$

where $A_{0}$ is a material constant, $\sigma_{0}$ is the initial stress, 
$n$ is the stress exponent and $Q_{0}$ is the apparent activation energy for imaginary initial strain rate. The measured values of $n$ are 5.0, 4.5, and 3.9, and $Q_{0}$ are 420, 330 and $330 \mathrm{~kJ} / \mathrm{mol}$ for $\mathrm{N} 1, \mathrm{~N} 2$ and $\mathrm{N} 3$ in this order.

It is to be noted that Eq. (4) is similar to the Dorn equation in the form, $\dot{\varepsilon}_{s}=A_{n} \sigma^{n} \exp (-Q / R T)$, which is valid for the steady state of creep observed under a constant stress. Endo et al. ${ }^{7)}$ have recently derived from a simple thought experiment that Eq. (4) is principally equivalent to the Dorn equation. They also pointed out that Eq. (4) deviates from the Dorn equation when the strain rate is so high that the structural change can not catch up the gradual increase in stress with the increase in strain. In the present study, the strain rate is of the order of $10^{-8} / \mathrm{s}$ so that it is plausible to view that Eq. (4) is equivalent to the state equation for steady state creep.

\subsubsection{Stress Exponent and Activation Energy for Creep}

So far accumulated researches on steady state creep show that pure metals and metal type solid solution alloys exhibit the stress exponent of about 5 while some solid solution alloys containing substitutional solute atoms with a relatively large solute-solvent size difference exhibit the stress exponent of about $3 .^{9)}$ The ratecontrolling mechanism of the former is generally accepted to be the recovery process of internal stress and that of the latter to be the motion of dislocations which drag their solute atmosphere around them. In the present case, once I-S pairs are formed around dislocations, they have to drag the I-S atmosphere behind them. In such a case, the I-S atmosphere may retard the dislocation motion and eventually their presence give rise to the increase in dragging stress because the mobility of I-S pairs is controlled by the diffusivity of substitutional atoms which are much slower than that of interstitial atoms. On the basis of the analogy with binary alloys containing solutes with a large size misfit, it may be acceptable to reason that the stress exponent is 3 when the rate controlling process is the motion of dislocations dragging $\mathrm{I}-\mathrm{S}$ atmospheres.

In contrast to the solid solution alloys above, particle strengthened materials sometimes exhibit quite a large value of stress exponent (larger than 10). Actually, Shi et $a{ }^{10)}$ showed that the stress exponent was about 10 in a $2.25 \mathrm{Cr}-1 \mathrm{Mo}$ steel and Masuyama et al. ${ }^{11)}$ also reported that the stress exponent of a $9 \mathrm{Cr}-1 \mathrm{Mo}-\mathrm{Nb}-\mathrm{V}-$ $\mathrm{N}$ steel was about 15 at higher stresses while it was about 3 to 5 at lower stresses.

Comparing with some reported results on particle strengthened ferritic steels, it is clear that the present results have two outstanding characteristics. Firstly, the stress exponents of the present steels are small in spite of the presence of precipitates. Secondly, they decrease with the increase in concentration of interstitial nitrogen atom. The latter fact is in accordance with the concentration dependence of stress exponent for the typical alloy type binary materials. ${ }^{12}$ ) These results may suggest that the motion of dislocations dragging their I-S atmospheres is responsible for the rate controlling process under the present experimental condition.
In the following, the activation energy for creep will be discussed. In general, activation energies for creep of single phase materials are close to those for selfdiffusion. However, those of materials containing dispersed particles are much higher than those of selfdiffusion when the applied stress approaches to their threshold stress. In the present case, the activation energy of $\mathrm{N} 2$ and $\mathrm{N} 3$ are close to that for a $2.25 \mathrm{Cr}-1$ Mo steel $(360 \mathrm{~kJ} / \mathrm{mol}){ }^{7)}$ whereas that of $\mathrm{N} 1$ is a little bit higher than the others although $\mathrm{N} 1$ has less precipitates. The reason for this is not clear; however, it seems plausible to ascribe it to the structural instability of a N1 steel as will be discussed below.

In general, the apparent activation energy for creep is different from that of true one as discussed by Čadek. ${ }^{13)}$ According to the concept of back stress, the activation energy is described as below;

$$
Q_{\mathrm{c}}=Q^{*}-R T-\frac{(n-1) R T^{2}}{G_{(T)}} \frac{d G}{d T}-\frac{n R T^{2}}{\sigma-\sigma_{\mathrm{b}(T)}}\left(\frac{\partial \sigma_{\mathrm{b}}}{\partial T}\right)_{\sigma},
$$

where $Q^{*}$ is the true activation energy for creep, $G$ is the shear modulus, and $\sigma_{\mathrm{b}}$ is the back stress composed of the internal stress and threshold stress. The third and fourth terms of the right hand side of Eq. (5) are the contributions from the temperature dependence of $G$ and back stress, respectively. By employing the shear modulus and its temperature dependence of $\alpha-\mathrm{Fe}$, the sum of the second and third therm of the right hand side is evaluated to be about $10 \mathrm{~kJ} / \mathrm{mol}$. Since the contribution of the second and third terms is nearly the same in all specimens, the larger activation energy of $\mathrm{N} 1$ is attributable to the contribution from the fourth term. As seen in Fig. 5, all steels studied here have a tempered martensitic structure composed of densely populated dislocations which are pinned down either by needle-like or globular precipitates. However, N1 alone has less precipitates and thus the structural instability with temperature, namely, the annihilation of dislocations, appears to be larger than the others. If this reasoning can be applied, the weaker thermal stability of N1 causes the higher temperature dependence of internal stress, i.e., negative value of $\partial \sigma_{\mathrm{b}} / \partial T$ in Eq. (5), and it inevitably causes the apparent activation energy to be higher than the others. There are controversial reports as for the contribution from the fourth term in Eq. (5), namely the contribution is large in $\mathrm{Fe}-25 \mathrm{mass} \% \mathrm{Cr}-35$ mass $\% \mathrm{Ni}^{14)}$ while it is small in $\mathrm{Fe}-21$ mass $\% \mathrm{Cr}-11$ mass $\% \mathrm{Ni}^{1}{ }^{15)}$ Further examination is to be needed for the dependence of apparent activation energy on the fourth term.

\subsection{Deformation Mechanism}

As for the strengthening mechanism operating in the present steels, there are at least three possible origins, namely the dislocation-dislocation interaction, the solid solution strengthening and the interaction between dislocations and precipitates. Since all of the specimens in the present study have tempered martensite structure containing highly populated dislocations, it is reasonable to view that the internal stress arising from these dislocations contributes some part of total flow stress. 
However, the latter two mechanisms, namely, the I-S effect $^{5)}$ and the Orowan mechanism ${ }^{16)}$ or Srolovitz mechanism $^{17)}$ will be discussed briefly.

\subsubsection{I-S Effect}

Strain rate may be expressed by the following equation when the creep rate is controlled by the viscous motion of dislocations.

$$
\dot{\varepsilon}=\rho_{\mathrm{m}} b \bar{v} / M
$$

where $\rho_{\mathrm{m}}$ is the mobile dislocation density, $b$ is the strength of Burgers vector, $\bar{v}$ is the mean velocity of the dislocation and $M$ is the Taylor factor. When dislocations drag their solute atmosphere behind them, the mean velocity is given by Cottrell ${ }^{18)}$ as below;

$$
\bar{v}=\frac{D k T \sigma^{*}}{68 N C G^{2} \eta^{2} R_{\mathrm{m}}^{6} b M},
$$

where $D$ is the relevant diffusion coefficient, $k$ is the Boltzmann's constant, $\sigma^{*}$ is the effective stress component in applied stress, $N$ is the number of atoms per unit volume, $C$ is the average concentration of solutes, $G$ is the shear modulus, $\eta$ is the size factor between the solute and the solvent atom, and $R_{\mathrm{m}}$ is the radius of the solvent atom.

In order to apply Eq. (7) to the I-S atmosphere, the concentration, $C$ in Eq. (7) must be replaced with that of I-S pairs. In the present case, the number of I-S pairs is reasonably assumed to be proportional to the concentration of the nitrogen atom because its chemical interaction energy to the chromium atom is large. Here, the elastic interaction of chromium and cobalt atoms to dislocations is neglected because the atomic radii of chromium or cobalt atom is about the same as that of iron atom. Equations (6) and (7) claim that the creep rate is inversely proportional to the soluble nitrogen concentration compared at a given combination of temperature, dislocation density and effective stress. To analyze the deformation mechanism of the present steels, effective stresses were measured by mechanical differential testings. Figure 6 shows the relationship between the logarithm of steady state creep rate and the soluble nitrogen concentration at a given effective stress, in which the vertical axis is normalized by the product of $k$ ( $=D k T / 34 N G^{2} \eta^{2} R^{6} M^{2}$ ) and the relevant dislocation density to eliminate the effect of dislocation density on the strain rate. It is seen that the slope of the line is

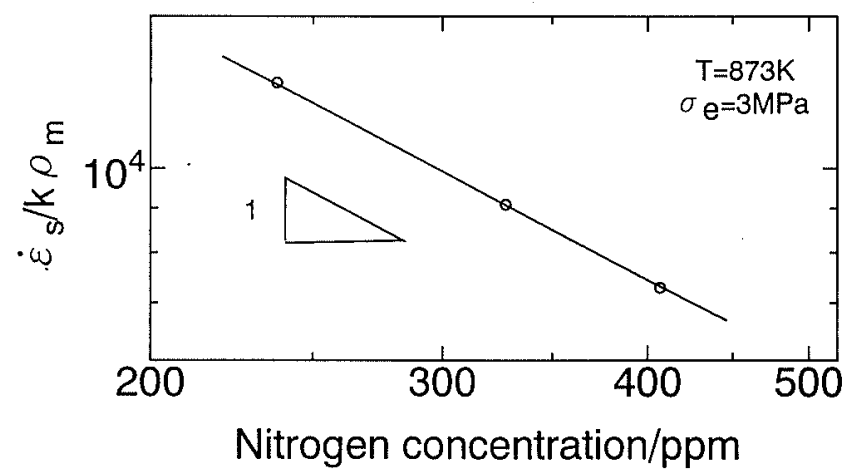

Fig. 6. Concentration dependence of steady creep rate ordered by dislocation density. The symbol $k$ is a constant. ${ }^{18)}$ close to -1 . This fact is quite favorable for the solute atmosphere dragging mechanism. The detail of the analysis with a reference to the effective stress will be given elsewhere. ${ }^{19)}$

\subsubsection{Dislocation-Particle Interaction}

As mentioned in Sec. 3.4, the various types of precipitates are observed within grains and along grain boundaries, and they seem to have the influence on the creep strength. As for the dislocation-particle interaction, there are two possibilities, namely the Orowan stress ${ }^{16)}$ and the attractive interaction between dislocations and incoherent dispersoids which was proposed by Srolovitz. ${ }^{17)}$ A recent study has revealed that the origin of threshold stress is ascribable to the Srolovitz mechanism in most cases. ${ }^{20)}$ In the present case, it is not yet clear that either the Srolovitz mechanism or the Orowan mechanism is responsible for the threshold stress because whether the chromium nitrides are coherent is unknown. However, the magnitude of threshold stress due to both mechanisms is much the same. So the Orowan stress was estimated as the threshold stress as below.

The Orowan stress for an edge dislocation is theoretically given as $^{8)}$;

$$
\frac{\sigma_{\text {or }}}{E}=\frac{0.8 M b}{4 \pi(1+v) \tau_{\mathrm{s}}}\left\{\ln \left(\frac{H}{r_{0}}\right)+0.7\right\}
$$

where $M$ is Taylor factor, $v$ is the Poisson ratio, $l_{\mathrm{s}}$ is the mean distance between particle centers, $r_{0}$ is the cut off radius of dislocation core and $H$ is the harmonic average between $2 r_{\mathrm{s}}$ and $1.25 l_{\mathrm{s}}$. The value of $l_{\mathrm{s}}$ and $r_{\mathrm{s}}$ determined from the TEM studies are given in Table 5 . By the use of these values and Eq. (8), and substituting 2.0, 0.28 and $1.0 \mathrm{~nm}$ for $M, v$ and $r_{0}$, respectively, the Orowan stress was estimated. The resultant values are 15, 22, 30 and $38 \mathrm{MPa}$ for $\mathrm{N} 1, \mathrm{~N} 2, \mathrm{~N} 3$ and $\mathrm{N} 4$, respectively. As it can be seen from this result, the stress level of about 15 to $40 \mathrm{MPa}$ comes from the interaction between particles and dislocations. This result shows that the dislocation-participate interaction contributes greatly to the total stress depending on the nitrogen contents; however, it has not been cleared yet whether their contribution is additive to the flow stress when the solid solution and dispersion hardening are both operating. Nakashima et al. ${ }^{21)}$ studied the high temperature deformation of $\mathrm{Al}-3 \mathrm{~mol} \% \mathrm{Mg}-1 \mathrm{~mol} \% \mathrm{Mn}$ alloys and showed that the effect of dispersion hardening decreases at lower temperatures and higher strain rates. This is because the fraction of dislocations which are not under the influence of dispersoids directly increases as the dislocation density becomes high. In contrast to the above case, a simple summation law is valid when the dislocation density is quite high so that the contribution of precipitates to the flow stress is expected to be smaller than the estimated values. With respect to this, further study is needed.

\section{Conclusion}

High temperature creep behavior of 9 mass $\% \mathrm{Cr}-2$ mass $\%$ Co steels containing high concentration of nitrogen was examined by constant load creep testing. The stress 
and temperature range is from 50 to $70 \mathrm{MPa}$, and 873 to $923 \mathrm{~K}$, respectively. The results obtained are as follows;

(1) Up to about $0.2 \%$ nitrogen can be forcibly added to $9 \% \mathrm{Cr}-2 \% \mathrm{Co}$ steel; however, 240 to $410 \mathrm{ppm}$ of nitrogen exists as solid solutions and the rest precipitates as chromium nitrides.

(2) An addition of nitrogen up to 0.16 mass $\%$ decreases creep rate and increases creep life. However, the addition of $0.2 \%$ nitrogen diminishes the creep life and it has little effects on minimum creep rate in comparison with the specimen containing $0.16 \%$ nitrogen.

(3) Logarithm of strain rate is proportional to the true strain over the extensive part of creep life. Thus the creep rate is expressed as;

$$
\dot{\varepsilon}=\dot{\varepsilon}_{0} \exp (S \varepsilon)
$$

Where $\dot{\varepsilon}_{0}$ and $S$ are the imaginary initial strain rate and the stress acceleration factor, respectively.

(4) Temperature and stress dependence of $\dot{\varepsilon}_{0}$ is expressed in the same form of the Dorn's equation;

$$
\dot{\varepsilon}_{0}=A_{0} \sigma_{0}^{n} \exp \left(-Q_{0} / R T\right) \text {. }
$$

The values of $n$ and $Q_{0}$ were 3.9 to 5.0 and 330 to $420 \mathrm{~kJ} / \mathrm{mol}$, respectively. However, these equation could not be applied in the specimen containing 0.19 mass $\%$ nitrogen.

(5) The Orowan stress is estimated from the distribution of the particle radius. The resultant values are 15 , 22,30 and $38 \mathrm{MPa}$ for the specimens containing 0.06 , $0.11,0.16$ and 0.19 mass $\%$ nitrogen, respectively.

\section{Acknowledgements}

The authors are indebted to Dr. Masahiro Ohgami of Nippon Steel Corporation, who kindly analyzed quantities of nitrogen and chromium solid solution of specimens. This work was partly supported by Grant-in-Aid of Fundamental Scientific Research (Kiban C, 19961997) from the Ministry of Education, Science and Culture of Japan, and also partly supported by the ISIJ Research Promotion Grant. These supports were greatly appreciated.

\section{REFERENCES}

1) Y. Otoguro: Met. Technol. (Jpn), 56 (1984), 15.

2) A. Iseda, H. Teranishi and F. Masuyama: Tetsu-to-Hagane, 76 (1990), 1076.

3) M. Kawai, K. Kawaguchi, H. Yoshida, E. Kanazawa and S. Mito: Tetsu-to-Hagané, 61 (1975), 229.

4) K. Monma and H. Sudo: J. Jpn. Inst. Met., 30 (1966), 558.

5) T. Motoyoshi, H. Sato and H. Oikawa: J. Jpn. Inst. Met., 57 (1993), 890.

6) K. Maruyama: J. Jpn. Inst. Met., 50 (1986), 701.

7) J. Seki and T. Endo: Tetsu-to-Hagané, 81 (1995), 862.

8) Y-H. Yah, H. Nakashima, H. Kurishita, S. Goto and H. Yoshinaga: J. Jpn. Inst. Met, 52 (1988), 1246.

9) S. Karashima: Bull. Jpn. Inst. Met., 18 (1979), 469.

10) J. Shi and T. Endo: Scr. Metall. 32 (1995), 1159.

11) F. Masuyama and M. Ohgami: Proc. of JIMIS-7, Nagoya, (1993), 325.

12) C. M. Sellers and A. G. Quarrel: J. Inst. Met., 90 (1961-62), 329.

13) J. Cadek: Bull. Jpn. Inst, Met., 26 (1987), 404.

14) Y. Kondo, T. Matsuo, and R. Tanaka: Tetsu-to-Hagané, 71 (1985), 1002.

15) E. Hajná, M. Pahutová and J. Čadek: Kovové. Mater, 23 (1985), 174.

16) E. Orowan: Dislocation in the Symp. on Internal Stresses in Metals and Alloys, Inst. Metals, London, (1948), 451.

17) D. J. Srolovitz, R. A. Petkovic-Luton and M. J. Luton: Philos. Mag., A48 (1983), 795.

18) A. H. Cottrell: Report of a Conf. on Strength of Solids, The Phys. Soc., (1948), 30.

19) K. Hara, F. Masuyama and T. Endo: in preparation.

20) E. Nakashima and H. Yoshinaga: Tetsu-to-Hagané, 77 (1991), 1349.

21) E. Nakashima, K. Iwasaki, S. Goto and H. Yoshinaga: J. Jpn. Inst. Met., 52 (1988), 180. 